\title{
Effect of high wavelengths low intensity light during dark period on physical exercise performance, biochemical and haematological parameters of swimming rats
}

\author{
W Beck, C Gobatto \\ Laboratory of Applied Sport Physiology, School of Physical Education, University of Campinas, \\ Sao Paulo, Brasil \\ Received: November 10, 2013 \\ Accepted: July 15, 2015
}

\begin{abstract}
Nocturnal rodents should be assessed at an appropriate time of day, which leads to a challenge in identifying an adequate environmental light which allows animal visualisation without perturbing physiological homeostasis. Thus, we analysed the influence of high wavelength and low intensity light during dark period on physical exercise and biochemical and haematological parameters of nocturnal rats. We submitted 80 animals to an exhaustive exercise at individualised intensity under two different illuminations during dark period. Red light ( $>600 \mathrm{~nm}$; $<15 \mathrm{ux})$ was applied constantly during dark period (EI; for experimental illumination groups) or only for handling and assessments (SI; for standard illumination groups). EI led to worse haematological and biochemical conditions, demonstrating that EI alone can influence physiological parameters and jeopardise result interpretation. SI promotes normal physiological conditions and greater aerobic tolerance than EI, showing the importance of a correct illumination pattern for all researchers that employ nocturnal rats for health/disease or sports performance experiments.
\end{abstract}

Keywords: rats, chronobiology, aerobic tolerance, haematology, environmental illumination, exercise

Many authors have postulated the existence of circadian rhythms for physical exercise performance $(12,32)$, however, some of them do not entirely agree $(10,41)$. Despite lack of consensus, a common point raised over the years is the presence of confounding effects that disturb experimental control in human model investigations involving exercise chronobiology $(12,17,32,41)$. In summary, confounding effects comprise social, nutritional, motivational and time-awake variations, masking the real chronobiological phenomena. In order to optimise such methodological control the animal model certainly becomes an interesting way.

Rat circadian rhythms are well characterised by high core body temperature $(25,36)$, spontaneous activity (21), food intake, heart rate and locomotion (25) during dark period, representing $62 \%$ of total sleep time in the daylight period (38). Circadian modulations of these parameters are mainly synchronised by environmental light for these mammals $(8,20,26)$. During the wakefulness period these nocturnal laboratory animals are usually kept under total darkness, promoting an optimum environment for the rat but adverse conditions for visualisation-based assessments. This condition encourages researchers to apply procedures under indiscriminate environmental light and time of day.

Correspondence: Claudio Gobatto

Laboratory of Applied Sport Physiology, School of Applied Sciences, University of Campinas, Pedro Zaccaria Street, 1.300, Jardim Santa Luíza - Postal Code: 13484-350 - Limeira - São Paulo, Brasil

Phone: +55-19-37016653; Fax: +55-19-37016680; E-mail: cgobatto@uol.com.br 
Observing this context, we have recently studied the influence of circadian rhythms on haematological parameters and physical exercise performance in rats. We found significant time of day influence, especially on white blood cells, also finding a higher time to exhaustion (at individually prescribed maximal aerobic capacity intensity) during wakefulness period when compared to sleep period for swimming rats (6). In this study, a special red light source was switched on only during assessments during wakefulness period. In order to assess these animals during dark period without promoting additional stress, some researchers have employed lights in the red spectrum believing that rats could not capture this wavelength (16). However, recent studies have found that even albino rats possessing rod-based vision (23) are sensible to different colours, including red (35). Moreover, if rats are submitted to a luminosity spectrum above $600 \mathrm{~nm}$ of very low intensity $\left(15 \mathrm{~W}, 170 \mu \mathrm{W} / \mathrm{cm}^{2}\right.$ of irradiance), low influence of circadian rhythm is found on melatonin secretion when compared to the same wavelength of high intensity $\left(100 \mathrm{~W} ; 1040 \mu \mathrm{W} / \mathrm{cm}^{2}\right)$ or white light (36).

Despite the importance of wavelength and intensity of light source, duration must also be considered, as short periods of bright light significantly influence rat circadian rhythms. One-minute pulse duration (150 lux) can reduce $30 \%$ of $\mathrm{N}$-acetyltransferase activity of the pineal gland when the light is applied during dark period (22), without major changes during light period (28).

Knowing the appropriate time of day to apply swimming tests for rats, the next step is to identify if environmental light significantly influences performance scores. So, this study aimed to verify the influence of a high wavelength and low intensity light source during dark period on physical exercise parameters of swimming rats. In addition, we investigated through physical exercise and biochemical and haematological parameters if it is more appropriate to switch this light on only during experimental procedures (in order to minimise the exposure) or all night in order to adapt to the light source. We hypothesised that constant red light during wakefulness period leads to worse performance and biochemical and haematological parameters when compared to red light switched on for assessments only.

\section{Materials and Methods}

\section{Animals and housing}

Eighty male albino Wistar rats (45 days old) were obtained from São Paulo State University and immediately kept under controlled environmental conditions $\left(22 \pm 1{ }^{\circ} \mathrm{C}, 45-55 \%\right.$ relative humidity, noise $<80$ decibels, and 4 or 5 animals per polypropylene cage). Water and rodent chow (70\% carbohydrate, $23.5 \%$ protein, 6.5\% fat, Purina 5008, St. Louis, MO) were continuously available. We conducted the experiment under the principles of laboratory animal care of the National College for Animal Experimentation and the American Physiology Society (2) recommendations; the project was approved by the institutional review board (018/2010).

\section{General procedures and experimental design}

From 45- to 75-day-old, animals were maintained under the previously described conditions in order to promote the environmental adaptation. We established an artificial daily photoperiod of 12 hours of bright light (06:00-18:00 h) and 12 hours of total darkness, with all maintenance procedures (cage cleaning and change, handling, adaptation procedures and 
physical exercise testing) conducted at 20:00 h to handle animals during their wakefulness period (36). This time of day was set based on time-course data of core body temperature and levels of spontaneous activity and sleep in rats investigated elsewhere $(21,36)$.

During light period we used a white lamp (Phillips ${ }^{\circledR}$, soft White, $2700 \mathrm{~K}, 565-590 \mathrm{~nm}$, $<60$ lux). For dark period the same light source was employed, surrounded by a special red filter (Rosco®, Stamford, CT, USA, mod.\#FIRE19), solely eliciting spectral energy above $600 \mathrm{~nm}$ and intensity of $<15$ lux measured by an environment meter (Instrutherm ${ }^{\circledR}$, São Paulo, SP, Brazil, mod.THDL 400). We placed the lamps carefully to permit the same light intensity for all cages.

The animals were divided into two groups: standard illumination (SI; $n=40$ ) and experimental illumination (EI; $n=40$ ). While the EI group was kept under constant red light during dark period (from 18:00 to 06:00 h), the SI group was only submitted to red light during handling or testing and for the shortest time as possible.

After water and physical exercise adaptation (from 76 to 89 days old) we submitted all animals to a lactate minimum test (LMT; 90 days old) according to Beck et al. (5) in order to individually determine the maximal aerobic capacity (40). Having accomplished that, we subdivided the rats into four groups: SI control (SIc); SI exercised (SIe); EI control (EIc) and EI exercised (EIe). Exercised groups were submitted to an exhaustive swimming trial at lactate minimum intensity (TE) 48 hours after LMT, while the control groups remained at rest (Fig. 1).

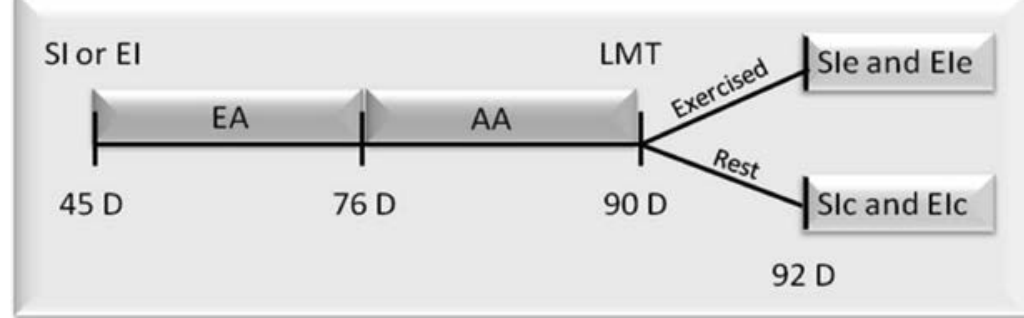

\footnotetext{
Figure 1. Schematic diagram of the experimental design. SI: standard illumination; EI: environmental illumination; D: days-old; EA: environmental adaptation; AA: aquatic adaptation; LMT: lactate minimum test; c: control; e: exercised.
}

\section{Swimming tests}

Aquatic and exercise adaptation consisted of progressive exposure to water (13 days; 10 to $\left.20 \mathrm{~min} ; 31 \pm 1^{\circ} \mathrm{C}\right)$ and progressive depth $(15,50$ and $120 \mathrm{~cm})$. This adaptation aimed at minimising thermal and handling stress beyond promoting continuous swimming behaviour.

The lactate minimum test (LMT) consisted of three steps: a) hyperlactataemia induction phase: two bouts of high intensity exercise (13\% body weight) separated by $30 \mathrm{~s}$, the first of $30 \mathrm{~s}$ duration and the second until exhaustion; b) recovery phase of nine minutes, aimed releasing the lactate produced from muscle to bloodstream; and c) incremental phase comprising progressive loads $(4,4.5,5,5.5,6$ and $7 \%$ bw) in five minutes stages with $30 \mathrm{~s}$ intervals to collect blood samples for lactate determination. Through blood lactate and exercise intensity we employed a second order polynomial function in order to determine the lactate minimum intensity ( $\mathrm{LMi}$; function's nadir interpolated to $\mathrm{X}$ axis), lactataemia for the lactate minimum test (LLM; nadir interpolation to $\mathrm{Y}$ axis) and determination coefficient $\left(\mathrm{R}^{2}\right)$. We considered 
success for LMT determination when the rat achieved at least three completed stages of the incremental phase, the first term of the polynomial function was positive and the $\mathrm{R}^{2}$ was $>0.80$, thereby determining the LMT success percentage $(\% \mathrm{~S})$ as described elsewhere (11).

We determined the physical exercise performance parameter (time to exhaustion; TE) as the time at which the animal maintained swimming at lactate minimum intensity. The exhaustion criterion was accepted by two experienced researchers, registered when the rat remained submerged for at least for $10 \mathrm{~s}$ while trying vigorously but unsuccessfully to emerge (27). Attenuation of the rat's righting reflex (9) concomitantly confirmed the exhaustion criterion. Blood samples were collected to determine lactate concentration before ([lac]pre) and after ([lac]post) TE. Once we aimed at analysing the endurance performance, we excluded the rats that swam for less than 20 minutes or showed discontinuous swimming behaviour from data analysis (2) as explained in the Results section.

\section{Biological material and biochemistry and haematological analysis}

We collected $25 \mu \mathrm{L}$ of blood samples from the distal tail of rats for determination of lactate concentration. The samples were immediately transferred to plastic tubes containing $400 \mu \mathrm{L}$ of trichloroacetic acid (4\%), prepared and measured at $340 \mathrm{~nm}$ against the calibration curve (14).

Animals were euthanised immediately after TE (exercised group) or at rest (control group) at the same time of day, in a carbonic gas chamber. A blood sample was collected by cardiac puncture (after thoracotomy), and the samples were rapidly transferred to polyethylene tubes containing $\mathrm{K}_{3}$ EDTA (FL Medical, Torreglia, PD, Italy). Red blood cells (RBC) count, haemoglobin $(\mathrm{Hb})$, haematocrit $(\mathrm{Hct})$, white blood cells (WBC) count and lymphocyte (Lymp) levels were determined by haemochromocytometry on a System XS-1000 automatic counter. Liver and skeletal muscle samples (gluteus maximus) were extracted to determine glycogen concentrations according to Dubois et al. (13).

\section{Statistical analysis}

All data were described as mean \pm standard deviation (SD). We analysed normal Gaussian distribution using the Kolmogorov-Smirnov test for all dependent variables and Levene's test for groups with different degrees of freedom to check homoscedasticity. These procedures conducted us to use parametric statistics, except for TE, which showed lack of normality even after $1 / x$, square root and log transformations. We analysed performance (TE) data by Wilcoxon test. LMT variables (LMi, LLM and $\mathrm{R}^{2}$ ) were compared between the SI and EI groups using T-tests for independent samples by groups, as well as for [lac]pre and [lac]post. Haematological and biochemical analysis was conducted using two-way ANOVA (luminosity and exercise main effects) applying the Newmann-Keuls post-hoc test when statistical significance for any main effect or interaction was found. All routines were performed with $\mathrm{p}<0.05$.

\section{Results}

Success percentage of lactate minimum determination was $85 \%$ for SI $(n=34)$ and $77.5 \%$ for those assessed under EI $(\mathrm{n}=31)$. We found no statistical differences between SI and EI for lactate minimum intensity $(4.83 \pm 0.48 \% \mathrm{bw}$ and $4.97 \pm 0.51 \% \mathrm{bw}$, respectively; $\mathrm{p}=0.214)$ and coefficient of determination $(0.96 \pm 0.05$ and $0.96 \pm 0.06$, respectively; $\mathrm{p}=0.80)$. Nevertheless, we found higher LLM for SI $(6.61 \pm 1.97 \mathrm{mmol} / \mathrm{L})$ in relation to EI $(4.06 \pm$ $1.03 \mathrm{mmol} / \mathrm{L} ; \mathrm{p}<0.01)$. 
Regarding TE, we found a significantly greater time for SIe in relation to EIe $(\mathrm{n}=15$, $97.94 \pm 52.50 \mathrm{~min}$; and $\mathrm{n}=14,46.62 \pm 25.16 \mathrm{~min}$, respectively; $\mathrm{p}=0.01$ ), as well as higher values for initial lactate concentration on SIe $(1.92 \pm 0.43 \mathrm{mmol} / \mathrm{L})$ in relation to EIe $(1.17 \pm$ $0.23 \mathrm{mmol} / \mathrm{L} ; \mathrm{p}<0.01)$. No significant differences were observed between groups for the final lactate concentration $(6.74 \pm 1.64 \mathrm{mmol} / \mathrm{L}$ and $5.68 \pm 1.29 \mathrm{mmol} / \mathrm{L}$, respectively; $\mathrm{p}=$ $0.06)$.

Results regarding tissue glycogen concentrations and haematological parameters are shown in Table I.

Table I. Mean and standard deviation of glycogen concentrations and haematological parameters of rats assessed under standard (SI) or experimental illumination (EI) and submitted (exercise)

or not (control) to acute exercise, with $\mathrm{p}$ and $\mathrm{F}$ values from ANOVA statistical analysis for these main effects and their interaction

\begin{tabular}{|c|c|c|c|c|c|c|c|c|c|c|}
\hline & \multicolumn{2}{|c|}{ SI } & \multicolumn{2}{|c|}{ EI } & \multicolumn{2}{|c|}{ Light effect } & \multicolumn{2}{|c|}{ Exerc. effect } & \multicolumn{2}{|c|}{ Interaction } \\
\hline & $\begin{array}{l}\text { Control } \\
(n=14)\end{array}$ & $\begin{array}{c}\text { Exercised } \\
(n=15)\end{array}$ & $\begin{array}{l}\text { Control } \\
(n=11)\end{array}$ & $\begin{array}{c}\text { Exercised } \\
(n=14)\end{array}$ & $\mathbf{F}$ & p & $\mathbf{F}$ & p & $\mathbf{F}$ & p \\
\hline $\begin{array}{l}\text { Liver } \\
(\mathrm{mg} / 100 \mathrm{mg})\end{array}$ & $\begin{array}{c}0.20 \pm \\
0.16\end{array}$ & $\begin{array}{l}0.05 \pm \\
0.03 \boldsymbol{\alpha}\end{array}$ & $\begin{array}{l}0.17 \pm \\
0.06 \boldsymbol{\beta}\end{array}$ & $\begin{array}{l}0.14 \pm \\
0.02 \boldsymbol{\beta}\end{array}$ & 1.25 & 0.27 & 14.25 & $<0.01$ & 6.13 & 0.01 \\
\hline $\begin{array}{l}\text { Muscle } \\
(\mathrm{mg} / 100 \mathrm{mg})\end{array}$ & $\begin{array}{c}0.09 \pm \\
0.05\end{array}$ & $\begin{array}{l}0.04 \pm \\
0.02 \boldsymbol{\alpha}\end{array}$ & $\begin{array}{l}0.03 \pm \\
0.01 \boldsymbol{\alpha}\end{array}$ & $\begin{array}{l}0.03 \pm \\
0.01 \boldsymbol{\alpha}\end{array}$ & 18.76 & $<0.01$ & 12.34 & $<0.01$ & 8.56 & $<0.01$ \\
\hline $\begin{array}{l}\mathrm{RBC} \\
\left(10^{12} / 1\right)\end{array}$ & $\begin{array}{c}8.34 \pm \\
0.41 \\
\end{array}$ & $\begin{array}{c}8.55 \pm \\
0.36 \\
\end{array}$ & $\begin{array}{c}8.60 \pm \\
0.37 \\
\end{array}$ & $\begin{array}{c}9.03 \pm \\
0.38 \boldsymbol{\alpha} \boldsymbol{\beta} \ell\end{array}$ & 11.31 & $<0.01$ & 8.57 & $<0.01$ & 0.96 & 0.33 \\
\hline $\begin{array}{l}\mathrm{Hb} \\
(\mathrm{g} / \mathrm{dl})\end{array}$ & $\begin{array}{c}14.82 \pm \\
0.47\end{array}$ & $\begin{array}{c}15.16 \pm \\
0.46\end{array}$ & $\begin{array}{c}15.34 \pm \\
0.59\end{array}$ & $\begin{array}{c}15.64 \pm \\
0.61 \boldsymbol{\alpha}\end{array}$ & 10.49 & $<0.01$ & 4.16 & 0.04 & 0.02 & 0.89 \\
\hline $\begin{array}{l}\text { Het } \\
(\%)\end{array}$ & $\begin{array}{c}47.21 \pm \\
2.08\end{array}$ & $\begin{array}{c}48.41 \pm \\
1.75\end{array}$ & $\begin{array}{l}51.65 \pm \\
1.32 \boldsymbol{\alpha} \boldsymbol{\beta} \\
\end{array}$ & $\begin{array}{l}52.97 \pm \\
2.59 \boldsymbol{\alpha} \boldsymbol{\beta}\end{array}$ & 56.57 & $<0.01$ & 4.40 & 0.04 & 0.01 & 0.04 \\
\hline $\begin{array}{l}\text { WBC } \\
\left(10^{9} / 1\right)\end{array}$ & $\begin{array}{c}6.70 \pm \\
1.67\end{array}$ & $\begin{array}{c}7.80 \pm \\
1.79\end{array}$ & $\begin{array}{c}9.05 \pm \\
2.47\end{array}$ & $\begin{array}{l}11.53 \pm \\
4.00 \alpha \beta \ell\end{array}$ & 13.30 & $<0.01$ & 4.62 & 0.04 & 0.69 & 0.41 \\
\hline $\begin{array}{l}\text { Lymp } \\
\left(10^{9} / 1\right)\end{array}$ & $\begin{array}{c}4.44 \pm \\
1.26\end{array}$ & $\begin{array}{c}4.95 \pm \\
1.14\end{array}$ & $\begin{array}{c}6.18 \pm \\
1.97\end{array}$ & $\begin{array}{c}8.32 \pm \\
2.89 \boldsymbol{\alpha} \boldsymbol{\beta} \ell\end{array}$ & 19.79 & $<0.01$ & 5.34 & 0.02 & 2.01 & 0.16 \\
\hline
\end{tabular}

$\alpha p<0.05$ in relation to SI control.

$\beta \mathrm{p}<0.05$ in relation to SI exercised.

$\ell \mathrm{p}<0.05$ in relation to EI control.

RBC: Red Blood Count (Erythrocytes); Hb: Hemoglobin; Hct: Hematocrit;

WBC: White Blood Count (Leucocytes); Lymp: Lymphocytes.

\section{Discussion}

The main finding of the present experiment was that environmental light undoubtedly leads to alterations in most of the parameters studied, physical exercise performance, biochemical and haematological scores, entirely confirming our initial hypothesis. We found higher aerobic tolerance at standard illumination and generally worse conditions for the animals exposed to experimental luminosity.

We found lactate minimum test scores quite similar to the literature $(2,11)$ and only the lactataemia corresponding to LMT was influenced by experimental illumination. A decrease in LLM has already been shown in human beings (37) and rats (38) with low stores of glycogen. Ahead of this, experiments with malnourished rats report approximately similar results (39), showing that physiologically adverse conditions are capable of decreasing 
lactate concentration, as occurred in our experiment. Lactataemia after TE was regulated by exercise and since the intensity was individually determined, the lactate responses were not statistically different.

Time to exhaustion at lactate minimum intensity was higher for animals maintained under standard illumination when compared to experimental illumination. We interpreted these results considering a multi-factorial view, once the glycogen stores and haematological variables measured in our experiment could directly influence this result. It is well known that the glycogen is the major energy substrate for our proposed exercise and some authors have associated the inability to continue exercise at the required intensity to a lack of energetic substrates, mainly glycogen depletion (15). In our study, the skeletal muscle glycogen content was decreased by the experimental luminosity (Table I). So, these animals started the exercise with low substrate in relation to SI animals, probably reflecting in the TE results. The variability of TE will certainly be the subject of further studies in our laboratory, but analysing our data it is clear that the EI leads to worse conditions for maintaining exercise, as shown by the haematological parameters.

Analysing blood cells, in general, we found that the exercise and experimental luminosity signalled a stressful situation. Scores found for control groups were close to those described in the specialised literature (7). Variations found were considered normal once we submitted the animals to two effects (luminosity and exercise) and haematological parameters are usually very sensible (30). Regarding red blood cells, the prolonged exercise generally promotes dehydration and the liquid loss consequently increases relative values (31), as found for red blood cells count, haematocrit and haemoglobin. The increase promoted by experimental illumination cannot be explained by data collected from our experiment and deserves more investigation; nevertheless, it is known that haematological parameters can be modulated by several factors, such as stress, circadian rhythm (34) or exercise (33).

The literature consistently associates high WBC counts with infection or inflammatory responses and it could set an individual's health status (4). These cells usually show a transitory increase in acute events such as physical exercise (19), generally associated with high catecholamine activity (18). Exercise responses are intensity, physical condition and duration-dependent (19), being catalysed in prolonged exercise by corticosterone secretion (29). Despite the acute phase modulation on WBC caused by exercise, we have shown that the lighting environment was capable of promoting these increases in a chronic manner, as found in some diseases. Light is a very important environmental signal for circadian rhythm, promoting significant physiological and behavioural alterations $(8,20,26)$. The high WBC counts in animals exposed to experimental illumination was probably generated by the stress of constant light during dark period, even through the light source was carefully determined. This result shows that the duration of light exposure during dark period is strong enough by itself to influence physical exercise performance and biochemical and haematological parameters.

Analysing the data set, we have found that the experimental illumination causes a higher WBC counts, which is associated with inflammation, infection or stress conditions. Stress exposure can stimulate the anterior pituitary gland, increasing the release of adrenocorticotropic hormone (ACTH) (1). This process is closely related to high levels of epinephrine and corticosterone secreted by the renal gland (3), generating an increase of glycolytic and glycogenolytic metabolism and consumption of high levels of glycogen at rest (24). Considering the chronic stress exposure (from 45 to 90 days old), lower glycogen concentrations were found in the skeletal muscle of EI groups at rest, leading to worse haematological conditions and performance (TE). 
Environmental light leads to modulation in physical exercise and haematological and biochemical parameters. The standard illumination was effective for animal visualisation for all procedures during dark period, promoting a normal range of haematological and biochemical parameters and a longer time to exhaustion at lactate minimum intensity. The experimental illumination proposed in the present study dramatically and negatively influenced most of the parameters investigated, promoting generally poor conditions when compared to the proposed standard illumination. Confirming our initial hypothesis, we postulate that environmental luminosity should be observed in nocturnal animal experiments in order to enhance methodological control and produce scientifically reliable results.

\section{Acknowledgements}

This study was supported by the São Paulo State Research Support Foundation (FAPESP) Proc. 2010/13377-7, 2011/13226-1 and 2012/20501-1.

\section{REFERENCES}

1. Aguilera G: Regulation of pituitary ACTH secretion during chronic stress. Front. Neuroendocrinol. 26, 321-350 (1994)

2. Kregel KC, Allen DL, Booth FW, Fleshner MR, Henrikson EJ, Musch TI, O'Leary DS, Parks CM, Poole DC, Ra'anan AW, Sheriff DD, Sturek MS, Toth LA: Resource book for the design of animal exercise protocols. American Physiology Society, Bethesda, USA (2006)

3. Axelrod J, Reisine TD: Stress hormones: their interaction and regulation. Science 224, 452-459 (1984)

4. Banfi G, Roi GS, Dolci A, Susta D: Behaviour of haematological parameters in athletes performing marathons and ultramarathons in altitude ('skyrunners'). Clin. Lab. Haem. 26, 373-377 (2004)

5. Beck WR, De Araujo GG, Gobatto CA: Methods of exercise intensity and lactataemia determination of lactate minimum test in rats. Comp. Exerc. Physiol. 8, 113-116 (2012)

6. Beck WR, Gobatto CA: Effects of maximum intensity aerobic swimming exercise until exhaustion at different times of day on the hematological parameters in rats. Acta Physiol. Hung. 100, 427-434 (2013)

7. Carvalho GD, Masseno APB, Zanini MS, Zanini SF, Porfírio C, Machado JP, Mauad H: Clinical evaluation of laboratory rats (Rattus norvegicus Wistar Strain): sanitary, biological and physiological parameters. Revista Ceres 56, 51-57 (2009)

8. Clough G: Environmental effects on animals used in biomedical research. Biol. Rev. 57, 487-523 (1987)

9. Coop SW, Hirai DM, Musch TI, Poole DC: Critical speed in the rat: implications for hindlimb muscle blood flow distribution and fibre recruitment. J. Physiol. 588, 5077-5087 (2010)

10. Dalton B, McNaughton L, Davoren B: Circadian rhythms have no effect on cycling performance. Int. J. Sports Med. 18, 538-542 (1997)

11. De Araujo GG, Papoti M, Manchado FB, Mello MAR, Gobatto CA: Protocols for hyperlactatemia induction in the lactate minimum test adapted to swimming rats. Comp. Biochem. Physiol. A 148, 888-892 (2007)

12. Drust B, Waterhouse J, Atkinson G, Edwards B, Reilly T: Circadian rhythms in sports performance - an update. Chronobiol. Int. 22, 21-44 (2005)

13. Dubois ML, Gilles KA, Hamilton JK, Rebbers PA, Smith F: Colorimetric method for determination of sugars and related substances. Anal. Chem. 28, 350-356 (1956)

14. Engel PC, Jones JB: Causes and elimination of erratic blanks in enzymatic metabolic assays involving the use of NAD in alkaline hydrazine buffers: improved conditions for the assay of L-glutamate, L-lactate, and other metabolites. Anal. Biochem. 88, 475-484 (1978)

15. Febbraio M, Dancey J: Skeletal muscle energy metabolism during prolonged, fatiguing exercise. J. Appl. Physiol. 87, 2341-2347 (1999)

16. Finley RB Jr: Observation of nocturnal animals by red light. J. Mammal. 40, 591-594 (1959)

17. Forbes-Robertson S, Dudley E, Vadgama P, Cook C, Drawer S, Kilduff L: Circadian disruption and remedial interventions. Sports Med. 42, 185-208 (2012)

18. Gabriel H, Schwarz L, Born P, Kindermann W: Differential mobilization of leucocyte and lymphocyte subpopulations into the circulation during endurance exercise. Eur. J. Appl. Physiol. 65, 529-534 (1992) 
19. Glesson M, Bishop NC, Stensel DJ, Lindley MR, Mastana SS, Nimmo M: The anti-inflammatory effects of exercise: mechanisms and implications for the prevention and treatment of disease. Nat. Rev. Immunol. 11, 607-615 (2011)

20. Huang H, Zhongfeng W, Weng S-J, Sun X-H, Yang X-L: Neuromodulatory role of melatonin in retinal information processing. Prog. Retinal Eye Res. 32, 64-87 (2013)

21. Ikeda M, Sagarab M, Inoué S: Continuous exposure to dim illumination uncouples temporal patterns of sleep, body temperature, locomotion and drinking behavior in the rat. Neurosci. Lett. 279, 185-189 (2000)

22. Ilnerová H, Vaněeccek J, Křeček J, Wetterberg, Sääf J: Effect of one minute exposure to light at night on rat pineal serotonin N-acetyltransferase and melatonin. J. Neurochem. 32, 673-675 (1979)

23. Jacobs GH, Fenwick JA, Williams GA: Cone-based vision of rats for ultraviolet and visible lights. J. Exp. Biol. 204, 2439-2446 (2001)

24. Rysińska J, Kołątaj A, Flak P: The influence of selection on reaction to stress in mice. I. Influence of triiodothyronine on glucose level in blood serum and aldolase and LDH activity in liver and kidney J. Anim. Breed. Genet. 109, 71-78 (1992)

25. Könczöl K, Pintér O, Ferenczi S, Varga J, Kovácz K, Palkovits M, Zelena D, Tóth ZE: Nesfatin-1 exerts longterm effect on food intake and body temperature. Int. J. Obesity 36, 1514-1521 (2012)

26. Lanfumey L, Mongeau R, Hamon M: Biological rhythms and melatonin in mood disorders and their treatments. Pharmacol. Ther. 138, 176-184 (2013)

27. Mcardle WD, Montoye HJ: Reliability of exhaustive swimming in the laboratory rat. J. Appl. Physiol. 21, 1431-1434 (1966)

28. Murphy PJ, Badia P, Myers BL, Boecker MR, Wright JR KP: Nonsteroidal anti-inflammatory drugs affect normal sleep patterns in humans. Physiol. Behav. 55, 1063-1066 (1994)

29. Pedersen BK, Bruunsgaard H, Klokker M, Kappel M, MacLean DA, Nielsen HB, Rohde T, Ullum H, Zacho M: Exercise-induced immunomodulation: possible roles of neuroendocrine factors and metabolic factors. Int. J. Sports Med. 18, S2-S7 (1997)

30. Pilny AA: Clinical hematology of rodent species. Vet. Clin. Exot. Anim. 11, 523-533 (2008)

31. Polat, Y: Effects of zinc supplementation on hematological parameters of high performance athletes. Afr. J. Pharm. Pharmacol. 5, 1436-1440 (2011)

32. Reilly T, Waterhouse J: Sports performance: is there evidence that the body clock plays a role? Eur. J. Appl. Physiol. 106, 321-332 (2009)

33. Schumacher YO, Schmid A, Gratfiwohl D, Bültermann D, Berg A: Hematological indices and iron status in athletes of various sports and performances. Med. Sci. Sports Exerc. 34, 869-875 (2002)

34. Smaaland R, Sothern RB, Laerum OD, Abrahamsen JF: Rhythms in human bone marrow and blood cells. Chronob. Int. 19, 101-127 (2002)

35. Sun JH, Yaga K, Reiter RJ, Garza M, Manchester LC, Tan DX, Poeggeler B: Reduction in pineal $\mathrm{N}$-acetyltransferase activity and pineal and serum melatonin levels in rats after their exposure to red light at night. Neurosci. Lett. 149, 56-58 (1993)

36. Tanaka H, Yanase M, Kanosue K, Nakayama T: Circadian variation of thermoregulatory responses during exercise in rats. Am. J. Physiol. Reg. Integr. Comp. Physiol. 258, 836-841 (1990)

37. Tegtbur U, Busse MW, Braumann KM: Estimation of an individual equilibrium between lactate production and catabolism during exercise. Med. Sci. Sports Exerc. 25, 620-627 (1993)

38. Van Luijtelaar ELJM, Coenen AML: An EEG averaging technique for automated sleep-wake stage identification in the rat. Physiol. Behav. 33, 837-841 (1983)

39. Voltarelli FA, Gobatto CA, Mello MAR: Determination of metabolic transition by lactate minimum test in malnourished rats during swimming exercise. Phys. Education Rev. 18, 33-39 (2007)

40. Voltarelli FA, Gobatto CA, Mello MAR: Determination of anaerobic threshold in rats using the lactate minimum test. Braz. J. Med. Biol. Res. 35, 1389-1394 (2002)

41. Youngstedt SD, O'Connor PJ: The influence of air travel on athletic performance. Sports Med. 28, 197-207 (1999) 
